\title{
Hacia un esquema de análisis de la formulación de la política social de salud pública desde un enfoque socio-territorial temporal a partir de los instrumentos de planificación ${ }^{*}$
}

Towards a framework of analysis

in the formulation of a social

politic in public health,

from a temporal socio-territorial perspective through the planification instruments

Jorge Enrique Martínez Carvajal** Jin Anthony Cotrino Sossa***

Recibido: 10 de Mayo de 2013

Aprobado: 28 de Agosto de 2013

* Cómo citar este artículo: Martinez, J. \& Cotrino, J. (2013). Hacia un esquema de análisis de la formulación de la política social de salud pública desde un enfoque socio-territorial temporal a partir de los instrumentos de planificación. Revista CIFE, 15(23), pp. 123-152.

** Economista, Magister en Política Social. E-mail: jorge.jemc@gmail.com, Director Centro de Investigaciones para el Desarrollo y la Innovación -CIDI-, Universidad Pontificia Bolivariana.

*** Economista, Magister en Ciencias Económicas. E-mail: jincotrino@usantotomas.edu.co, Decano de la Facultad de Economía de la Universidad Santo Tomás. 


\section{Resumen}

Garantizar el derecho a la salud constituye uno de los mayores retos para el Estado Colombiano y una de las mayores causas de conflictividad social, si bien se han creado sistemas y mecanismos de protección, no han sido suficientes para satisfacer el acceso a dicho derecho. Sin embargo, con el proceso de descentralización se han delegado competencias a entes territoriales que realizan actividades adicionales a lo estipulado en los requisitos mínimos sectoriales que define el Ministerio de Salud y Protección Social, respondiendo así, a la visión propia de los habitantes de un territorio sobre un problema.

Las iniciativas que se han emprendido en algunos casos, son innovadoras porque amplían los servicios o definen nuevos mecanismos de intervención para lograr mayor efectividad en las actividades y proyectos de salud pública.

El objetivo del artículo es proponer un esquema de análisis en salud pública desde un enfoque socio-territorial temporal, el cual se aborda desde los instrumentos de planificación sectorial y territorial, identificando las concordancias, desfases, continuidad y rupturas entre estos, basándose en los determinantes en salud de la Organización Mundial de la Salud (OMS).

Palabras clave: análisis cognitivo de políticas públicas, salud pública, planificación territorial.

Glasificación JEL: I18, H75

\section{Abstract}

Guarantee the right to health is one of the biggest challenges for the Colombian state and one of the biggest causes of social conflict. Although systems and protection mechanisms have been created, those have not been sufficient to meet the access to that right. However, with the decentralization process, powers have been delegated to local authorities which perform additional activities to what has been stipulated in the sectorial minimum requirements defined by the Ministry of Health and Social Protection, in response to the vision of thein habitants of a territory about a problem.

The initiatives that have been undertaken in some cases are innovative as those expand the services or define new mechanisms of action to achieve greater effectiveness in the activities and public health projects.

The aim of this paper is to propose a scheme of analysis in public health from a temporary socio-territorial approach, which is addressed from instruments of territorial and 
sectorial planning, identifying commonalities, gaps, continuity and ruptures between these, based on the determinants of health by the World Health Organization (WHO).

Keywords: cognitive analysis of public policy, public health, territorial planning.

Classification JEL: I18, H75

\section{Introducción}

En Colombia, la oferta en salud se encuentra definida por un Sistema General de Seguridad Social (SGSS) que es administrado y regulado por las directrices nacionales y sectoriales del Ministerio de Salud y Protección Social, pero las acciones de prevención, promoción e intervenciones colectivas, tienen un mayor rango de acción en las actividades de las entidades territoriales, tales como distritos, departamentos o municipios.

Visibilizar los instrumentos de planificación territoriales y sectoriales en salud es clave para entender la complejidad del sistema, motivo por el cual es necesario contar con un esquema de análisis que permita ampliar la perspectiva de las políticas de salud pública desde un enfoque socio-territorial temporal, propiciando una mejor comprensión de los objetivos y propósitos de acción en relación al cuidado, prevención y manejo de la salud pública.

Ahora bien, la propuesta de esquema se basa en la construcción de dicho esquema de análisis, tomando los instrumentos de planificación como objetos de análisis, siendo estos los que orientan las acciones tanto territoriales como sectoriales, que definen alcances y propósitos en un marco temporal. De igual manera, la lectura de los instrumentos por medio del análisis cognitivo de las políticas públicas, permite identificar diferentes tipos de referencial: global, sectorial, territorial global y secterritorial.

Este artículo se soporta en el grupo de investigación inter-facultades de Políticas Urbanas, común a la Facultad de Ciencia Política y Relaciones Internacionales y la Facultad de Arquitectura y Diseño ${ }^{1}$, que ha desarrollo y explorado el análisis cognitivo de políticas públicas propuesto por Muller en temáticas como: servicios públicos, vivienda, educación, políticas de infancia, espacio público y movilidad, profundizando en las políticas públicas urbanas y sociales. Abordar la salud desde esta óptica constituye un avance en el entendimiento de las relaciones y de los procesos propios de un sector y de un territorio, en cuanto a la mirada de la política social de salud pública.

Se realizó una revisión del sistema normativo en salud y de las competencias propias referidas a los niveles sectorial y territorial definidos en instrumentos de planificación,

1 Pontifica Universidad Javeriana. 
y una extensa revisión bibliográfica de las experiencias nacionales e internacionales en relación a la planificación territorial de salud pública. Partiendo de esto, se llevó a cabo una profunda reflexión sobre el esquema de análisis y su posterior ilustración, el cual debía ser sencillo para la comprensión de cualquier instancia o persona, a partir de un análisis cualitativo, el cual se realiza desde los instrumentos normativos (planes sectoriales y territoriales).

De esta manera, el análisis conceptual de los instrumentos de planificación permiten realizar una reflexión sobre la evolución de los alcances territoriales y sectoriales en salud pública, abriendo una discusión, no solo en relación al sistema de aseguramiento o a la eficacia en la ejecución de recursos, sino sobre los alcances y lógicas que están siendo predominantes en el desarrollo y progresividad del derecho a la salud.

El esquema se basa en el análisis cognitivo de las políticas públicas y de los determinantes en salud definidos por la OMS, bajo los cuales se definen las categorías de análisis de los instrumentos de planificación, lo que permite proceder con el análisis de la coordinación sincrónica y diacrónica, identificando la coherencia, correspondencia o concordancia en los instrumentos de planificación.

Se abordará la propuesta de esquema de análisis de la política social de salud pública que se fundamenta en los conceptos teóricos descritos en el capítulo uno de esta investigación, que son la base para examinar la articulación y trayectoria de la política de salud. Este capítulo se divide en cinco partes donde se realiza la descripción de los componentes del esquema de análisis. La primera parte se trata de los principios básicos bajo los cuales se desarrolla el esquema de análisis, definiendo así el alcance del mismo.

Para la segunda parte se lleva a cabo la descripción de los determinantes en salud y el modelo que se adopta para el análisis desde un enfoque sectorial-territorial, que servirán de categorías de análisis para los referenciales: global, sectorial, territorial y sectorial-territorial.

En la tercera parte se realiza la adaptación del modelo socio-territorial de Monnet para la salud pública, como marco de análisis, desde un abordaje territorial para la interdeterminación entre territorio, territorialidad y territorialización, que permite capturar las condiciones particulares e irrepetibles de un territorio, área geográfica o ciudad.

En la quinta parte se presenta el esquema de análisis de la política social de salud desde un enfoque socio-territorial temporal. La propuesta es una herramienta de análisis que permite identificar la evolución de la política social de salud pública, en relación al territorio, el tiempo y las dos lógicas de regulación bajo las cuales se define. El propósito de abordar la salud pública desde un enfoque territorial, tiene como propósito evidenciar los cambios y las diferencias en el abordaje de las dificultades en salud pública que 
afronta un territorio, y las adaptaciones e interpretaciones que se dan para garantizar el derecho a la salud.

Finalmente se presentan las conclusiones sobre el ejercicio desarrollado para la política social de salud pública y su relación con los procesos de territorialización y coordinación entre los diferentes instrumentos de planificación.

\section{Principios y supuestos iniciales para el análisis de la política social de salud pública desde un enfoque territorial y temporal}

Para el desarrollo del esquema se parte de unos principios básicos que soportan el desarrollo, la relación y la interpretación de los conceptos abordados, permitiendo definir unos parámetros de acción e interpretación. Para mayor comprensión de los principios, se dividen en tres grupos: uno en relación a las lógicas de regulación sectorial y territorial, el segundo en relación al análisis cognitivo de las políticas públicas y el último en relación a la salud pública. Finalmente se aborda la relación entre los instrumentos de planificación que serán objeto de análisis en la propuesta de esquema de análisis, los cuales son sectoriales y territoriales.

\subsection{Principios en relación a las Lógicas de Regulación Sectorial y Territorial}

- Los instrumentos de planificación de orden sectorial realizan una asignación de metas y resultados para un sector, el cual se define para orientar las acciones de forma global, siendo las entidades territoriales las que llevan a cabo las acciones y la administración de los recursos (SGP y rentas propias).

- La planificación de orden territorial, basa su desarrollo sobre las caracterices físicas, sociales, económicas y culturales, relacionándose de forma intersectorial.

- La Coordinación Sincrónica se da entre diferentes instrumentos de planificación, los cuales se encuentran en niveles diferentes del sector salud, por lo que se requiere coordinación en metas y resultados, así hayan sido elaborados en tiempos disimiles. Bajo esta óptica se evidencia la capacidad de los actores a imponer una lógica y las incoherencias o contradicciones propias de un sistema.

- La Coordinación Diacrónica se realiza desde una perspectiva histórica, donde se identifica la continuidad o rupturas en las acciones públicas en el territorio, que se caracteriza por el análisis de instrumentos que se regulan bajo una misma lógica y que se realiza en un período de tiempo definido, permitiendo identificar los cambios en el referencial. 
ISSN: 0124-3551 / Año 15, No 23 / julio-diciembre / pp. 123-152

- El análisis sincrónico y diacrónico permite entender de forma más amplia las dos lógicas de regulación sectorial y territorial, entendidas de forma sistemática las relaciones verticales y horizontales del referencial de las políticas sociales de salud pública. Generando así, discontinuidades cronológicas evidentes en el territorio, por las decisiones y acciones sucesivas y paralelas que se llevan a cabo sobre el mismo, concibiendo esto como la territorialización.

- Comprendiendo que las acciones en el territorio se dan de forma secterritorial, lo que implica una combinación de lógicas de regulación y la coordinación sincrónica y diacrónica, que se reflejan en los procesos de territorialización como lo define Monnet, de acuerdo a la orientación pública: de llevar a cabo acciones oportunas y no aisladas.

\subsection{Principios en relación a las Dimensiones Cognitivas de la Acción Pública}

- De acuerdo a Bejarano (2012), el análisis de la acción pública desde la perspectiva de los instrumentos de planificación, es un método para identificar y analizar los cambios en la construcción del referencial o de las formas de territorialidad.

- Un instrumento de acción pública se incorpora como un instrumento de gobierno que se desarrolla y esboza en los instrumentos de planificación. Siendo estos últimos los que definen las herramientas técnicas y sociales bajo las cuales se realiza la asignación de acciones, metas, resultados y presupuesto. Estos instrumentos son de orden territorial, toda vez que cuentan las asignaciones descritas.

- En las representaciones que se dan en los instrumentos de planificación, se pueden identificar los valores y normas sociales que median en la sociedad, en las cuales se realiza la jerarquización de problemas que permiten entender la lógica que predomina.

- El referencial en los instrumentos de planificación sectorial y territorial (políticas públicas) se relaciona con los determinantes en salud, que para este esquema de análisis son: estilo de vida, sistema de salud pública, medio ambiente y condiciones socioeconómicas. Bajo la lógica del análisis cognitivo de las políticas públicas se deben identificar los niveles de percepción: valores, normas, algoritmos e imágenes.

- El referencial que se identifica y construye para uno de los atributos de la ciudad, como lo es la salud pública y su representación en el referencial territorial global (RTG), el cual articula y regula dimensiones sociales en un proyecto concertado de territorio.

- El referencial territorial sectorial (RTS), se articula con dos lógicas: la sectorial y la territorial, siendo la última la de mayor grado de influencia, realizando avances en áreas 
que no se han explorado bajo la lógica sectorial, lo que permite identificar atributos urbanos, resultantes de procesos de coordinación y concertación entre el RTG (factor principal) y el RS (factor secundario).

- El referencial sectorial territorial (RST) se articula con dos lógicas: la sectorial y la territorial, siendo la primera la que lo define, puesto que esta se articula con las metas, los propósitos y resultados de la lógica sectorial, lo que impone la especialidad sobre los atributos territoriales y se define en el proceso de coordinación y concertación entre el RS (factor principal) y el RTG (factor secundario).

- Los conflictos, incoherencias y contradicciones entre los referenciales, permiten identificar las tensiones propias de los procesos de negociación, transformación e innovación en la política de salud pública, ya que se yuxtaponen dos lógicas de regulación: valores y condiciones espaciales, sociales y culturales diversas.

\subsection{Principios en relación a la Salud Pública}

- Los determinantes en salud intermedios son el referente para realizar el análisis de salud pública. Siguiendo el Modelo de Dahlgren y Whitehead se habla de la esfera colectiva de la salud, que se aborda a partir de instrumentos de planificación.

- Se definen cuatro categorías de análisis para los determinantes intermedios en salud, que son de impacto en el corto y mediano plazo: estilo de vida, sistema de salud pública, medio ambiente y condiciones socioeconómicas, descritos por la Comisión de Determinantes en Salud de la OMS.

- El análisis para la salud pública se relaciona estrechamente con las acciones y competencias propias en los diferentes niveles de planificación, identificados como nacional, sectorial, territorial y secterritorial, definidos por su escala de acción espacial, temática y regulación ejercida.

- La progresividad en la prestación de los servicios de salud y de garantías de un derecho no se realiza de forma homogénea en un país, la reglamentación que lo define en Colombia es: Ley 152 de 1994, Ley 715 de 2001, Decreto 1151 y 1122 de 2007, Decreto 1414 de 2010, el Decreto 3039 de 2007 y la Resolución 412 de 2000; las cuales regulan competencias y alcances en la planificación de la salud pública, puesto que se refieren a responsabilidades presupuestarias, de vigilancia y control de la salud.

- La lógica sectorial establece el desarrollo de instrumentos como: Plan Nacional de Salud Pública (Ley 1122 de 2007, Art. 33) y Plan de Salud Territorial (Resolución 425 de 2008), que deben estar articulados para el mejoramiento del estado de salud de los ciudadanos, permitiendo la mayor coherencia entre acciones y metas. 


\subsection{Instrumentos objeto de análisis y relación}

En la figura 8 se describe la relación y los instrumentos que se tendrán en cuenta para realizar el análisis. Definiendo las jerarquías y articulaciones según la Ley y los procedimientos.

Figura 8. Relación entre los instrumentos objeto de análisis

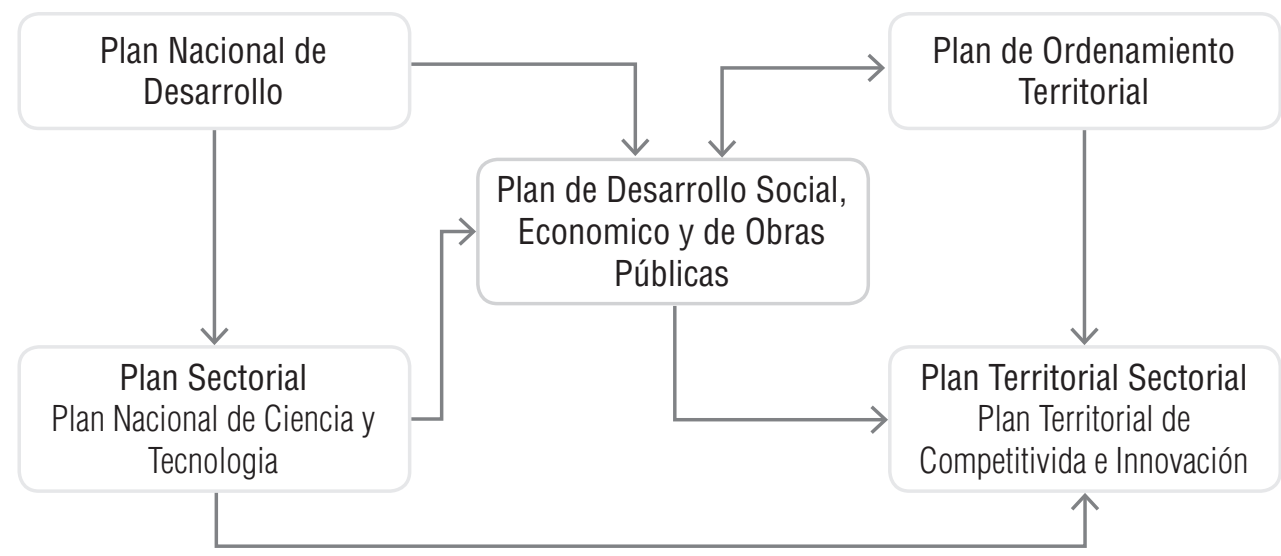

Elaboración propia

Para entender las relaciones que se constituyen entre los instrumentos de planificación se realiza la siguiente descripción:

- Plan Nacional de Desarrollo (PND), tiene como objetivos, de acuerdo con la Ley 152 de 1994, definir los objetivos nacionales y sectoriales de la acción estatal a mediano y largo plazo, según resulte del diagnóstico general de la economía y de sus principales sectores y grupos sociales; establecer las metas nacionales y sectoriales de la acción estatal a mediano y largo plazo y los procedimientos y mecanismo generales para lograrlos.

- Plan Nacional de Salud Pública (PNS), de acuerdo a la Ley 1122 de 2007, tiene como objetivo la atención y prevención de los principales factores de riesgo para la salud y la promoción de condiciones y estilos de vida saludables, fortaleciendo la capacidad de la comunidad y la de los diferentes niveles territoriales para actuar.

- Plan de Desarrollo, Económico y de Obras Públicas Territorial, de acuerdo a la Ley 152 de 1994, define que su radio de acción cubre la extensión de un territorio, que se relaciona con los aspectos económicos, sociales y culturales. Estos planes de desarrollo estarán conformados por una parte estratégica y un plan de inversiones. Estos deben tener coherencia y articulación con la planeación nacional y la de las entidades territoriales. 
- Plan de Salud Territorial, de acuerdo al Decreto 3039 de 2007, tiene como objetivo identificar opciones de mejora en la salud, focalizar necesidades de asistencia técnica, generar planes de mejoramiento, concertar un Plan de Asistencia Técnica a todos los actores del sistema de protección social y entender el plan como un instrumento para el mejoramiento del estado de salud de la población. Estos están a cargo de las direcciones territoriales de salud, articulando el enfoque poblacional, de determinantes y de gestión social del riesgo.

- Plan de Ordenamiento Territorial (POT), de acuerdo a Morcillo (2002), este trata los asuntos básicos que se relacionan con la ocupación y uso del suelo, el manejo y aprovechamiento de los recursos naturales, la protección del medio ambiente, la dotación y distribución de los servicios de agua potable, alcantarillado, energía y comunicaciones, el equipamiento y suministro de los servicios de educación, salud, recreación, seguridad, mercados, abastecimientos, entre otros. Finalmente la Ley 388 de 1997 define el objeto del ordenamiento del territorio, que complementa la planificación económica y social con la dimensión territorial, racionaliza las intervenciones sobre el territorio y orienta su desarrollo y aprovechamiento sostenible.

\section{Análisis de los determinantes de salud pública desde un enfoque sectorial-territorial}

Para definir un marco de análisis para los determinantes sociales que afectan la salud pública o sus resultados, se toman dos propuestas de análisis de determinantes en salud, y como base se toma la propuesta de Dahlgren y Whitehead que desarrolla Omiso (2007), donde las desigualdades sociales en la salud son el resultado de interacciones entre diferentes niveles de condiciones causales, desde el individuo a las comunidades y al nivel de políticas de salud pública. Es así como abordar diferentes niveles permite diferenciar escalas de decisión, cambio y acción de actores en un momento específico.

Complementando el esquema descrito en la propuesta de la Comisión de Determinantes en Salud de la OMS, se definen determinantes estructurales e intermedios en salud, los primeros hacen referencia a la cohesión social, educación, sistema de aseguramiento y estratificación social; para el segundo se define hábitat, saneamiento básico, promoción de salud, PIB-percapita, acciones colectivas en salud y desarrollo humano. Estos elementos se incorporan como dos niveles superiores en el modelo propuesto por Dahlgren y Whitehead (2001). La figura 1 ilustra la complementariedad en los modelos de análisis. 
Figura 1. Modelo Dahlgren y Whitehead - Determinantes en Salud

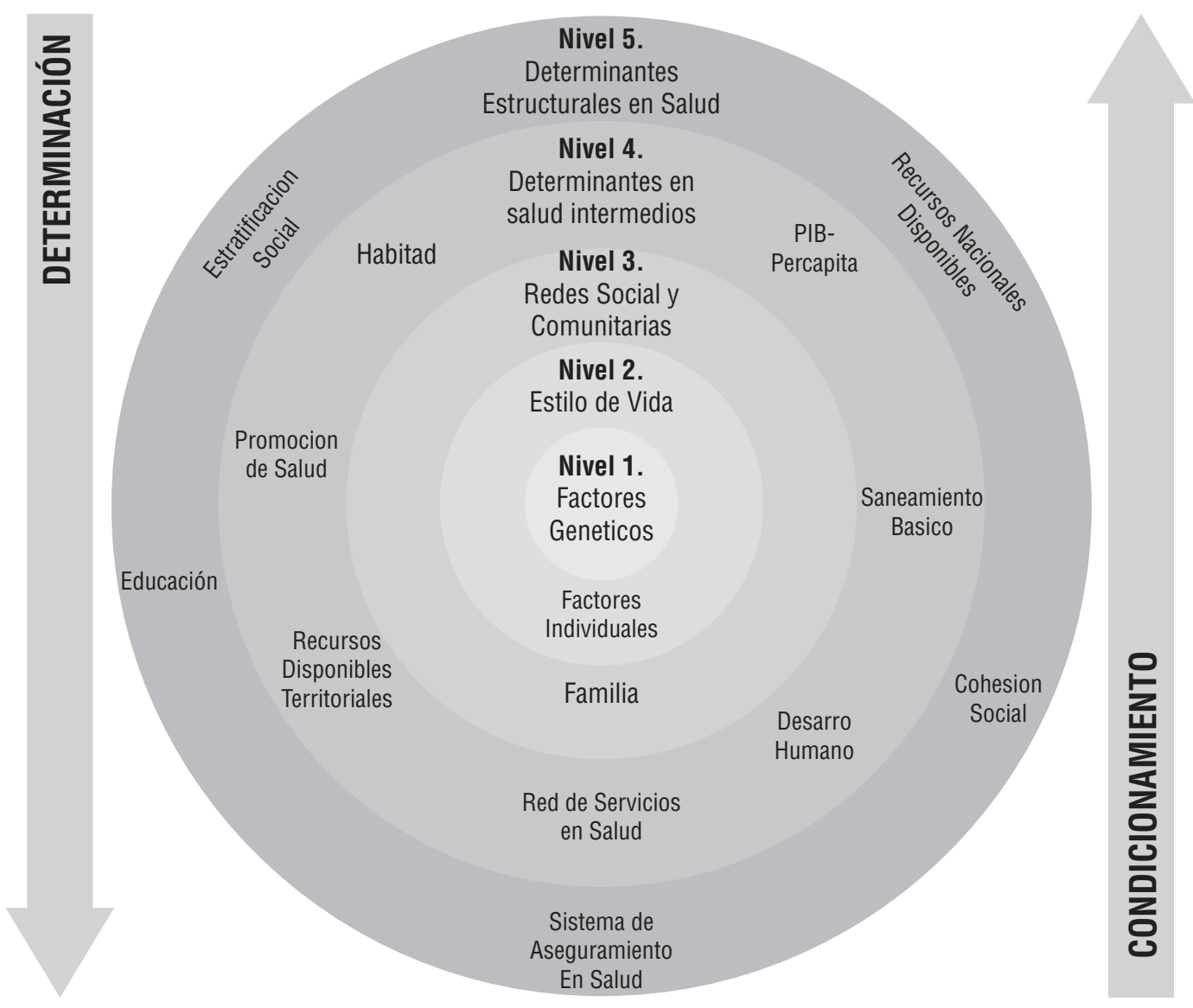

Fuente: Elaboración propia a partir de Moisso (2007) y Dahlgren y Whitehead (2001)

Definiendo así, cinco niveles de interacción para los determinantes en salud, que van desde lo genético hasta lo estructural. Esta investigación se centra en el Nivel 4, el cual permite identificar las acciones que se pueden emprender desde el ámbito territorial para incidir en los determinantes en salud.

Entendiendo el modelo desde una óptica sectorial y territorial, a partir del Nivel 4 como principal elemento de análisis en la salud pública territorial que se relaciona estrechamente con las acciones y competencias propias a nivel territorial, los determinantes intermedios en salud donde se especifican cuatro categorías: estilo de vida, sistema de salud pública, medio ambiente y condiciones socioeconómicas. 
Figura 2. Política de Salud Territorial a partir de determinantes en salud

Politica Sectorial de Salud

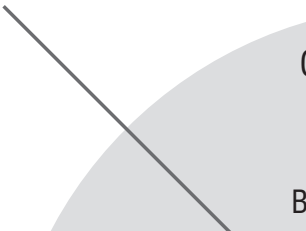

\section{Comportamiento -}

Estilo de Vida

Valores

Barreras para adoptar

condiciones de vida

Sistema de

saludables Salud Pública

\section{Politica}

Red de Servicios Aseguramiento Disponibilidad de recursos territoriales a salud

Territorial de Salud Pública

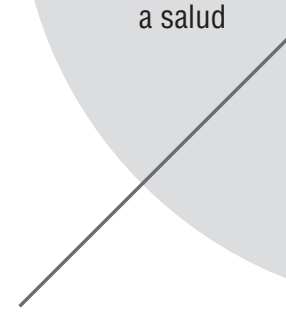

\section{Elaboración propia}

La figura 2 ilustra claramente los componentes que la integran, realizando una descripción detallada de cada categoría y su relación con la política territorial y sectorial de salud pública.

En relación, se definen competencias y responsabilidades para cada categoría, tomando la guía para la construcción de los planes territoriales del Ministerio de la Protección Social en el 2008, se pueden identificar algunas competencias que se señalan en la tabla 1 . 
Tabla 1. Competencias por categoría de determinante en salud. Definidas en la guía para la construcción de los planes de salud territoriales

\begin{tabular}{|c|c|c|}
\hline Categoría & Política Sectorial & Política Territorial \\
\hline $\begin{array}{l}\text { Comportamiento } \\
\text {-estilo de vida }\end{array}$ & $\begin{array}{l}\text { Definir las acciones que integran } \\
\text { el Plan de Salud Pública de } \\
\text { Intervenciones Colectivas. }\end{array}$ & No define nada. \\
\hline \multirow[t]{2}{*}{$\begin{array}{l}\text { Sistema de salud } \\
\text { pública }\end{array}$} & $\begin{array}{l}\text { Adquirir y distribuir, directamente } \\
\text { o a través de terceros, los biológicos } \\
\text { del Programa Ampliado de } \\
\text { Inmunizaciones (PAI). }\end{array}$ & $\begin{array}{l}\text { Coordinar el desarrollo y operación } \\
\text { de la vigilancia en salud en sus } \\
\text { componentes de vigilancia en } \\
\text { salud pública, vigilancia sanitaria e } \\
\text { inspección, vigilancia y control en } \\
\text { la gestión del Sistema General de } \\
\text { Seguridad Social en Salud (SGSSS) en } \\
\text { su jurisdicción. }\end{array}$ \\
\hline & & $\begin{array}{l}\text { Adoptar las normas técnico- } \\
\text { científicas, administrativas y } \\
\text { financieras que para la ejecución del } \\
\text { Plan de Salud Territorial defina el } \\
\text { Ministerio de la Protección Social. }\end{array}$ \\
\hline Medio ambiente & $\begin{array}{l}\text { Definir y desarrollar en coordinación } \\
\text { con los actores intra y extrasectoriales, } \\
\text { los componentes que fortalecerán la } \\
\text { capacidad nacional para cumplir con } \\
\text { el Reglamento Sanitario } \\
\text { Internacional. }\end{array}$ & $\begin{array}{l}\text { Ejercer la autoridad sanitaria para } \\
\text { garantizar la promoción de la salud } \\
\text { y la prevención de los riesgos y la } \\
\text { recuperación y superación de los } \\
\text { daños en salud en su jurisdicción. }\end{array}$ \\
\hline
\end{tabular}

Fuente: Elaboración propia a partir del Ministerio de la Protección Social (2008)

Si bien los determinantes se deberían relacionar con la política sectorial de salud y territorial, estas se limitan a funciones de vigilancia y control, lo que limita la interpretación de estos a partir de los planes de salud territorial si se ciñen a estas competencias. Este elemento se debe explorar con mayor profundidad, ya que las entidades territoriales han ampliado nuevos conceptos y coberturas en salud.

Este es el punto de partida para el análisis en salud pública, con el cual se brinda el marco y las categorías que se desarrollan en el análisis del Referencial sectorial, territorial y secterritorial. 


\section{Análisis de las lógicas de regulación sectorial y territorial a partir del referencial de las políticas públicas}

Para el análisis de los referenciales en relación a la salud, se toman los cinco niveles de percepción constituidos por el Referencial Global (RG), Sectorial (RS), Global Territorial (RGT) y secterritorial que se componen por el Referencial Sectorial Territorial (RST) y el Referencial Territorial Sectorial (RTS) referidos en la Política de Salud Pública, en sus diferentes escalas.

Es así que a partir de la propuesta de Muller (2010) descrita en el capítulo uno, se realiza la adaptación para la política de salud de los niveles de percepción. Para ilustrar las relaciones se proponen los siguientes elementos:

Figura 3. Niveles de percepción del referencial en la Política Pública en relación a la Salud Pública

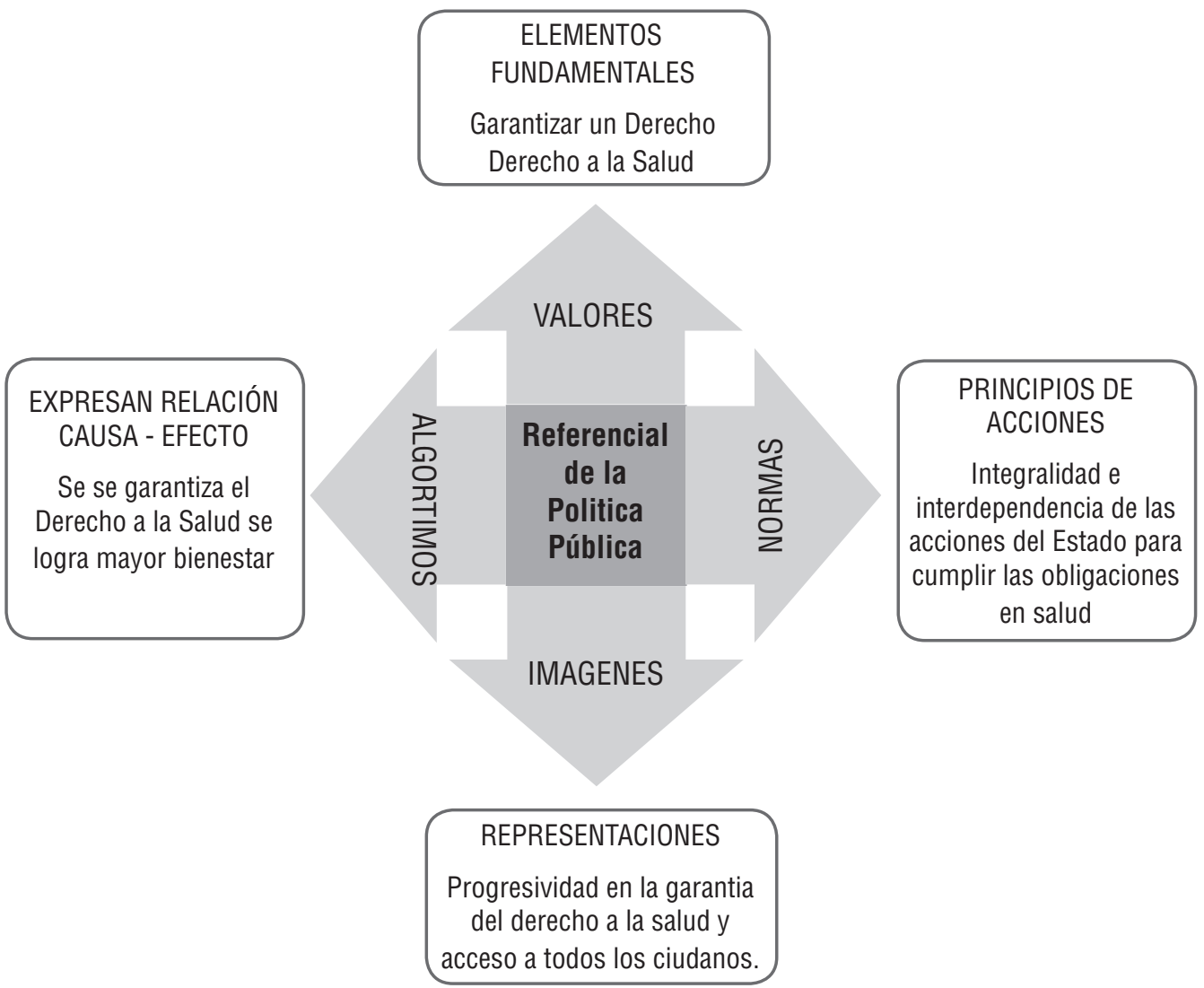

Fuente: Adaptacion propia a partir de Roa (2011) 
Para definir cada nivel de percepción se debe tener en cuenta:

- Valores: es un primer nivel de percepción que según Muller (2010), son "las representaciones fundamentales sobre lo que es bien y lo que es mal, lo deseable o lo que está por descartar” (p. 64).

En este caso estarían orientados a definir un estado de salud adecuado para la población, para el bienestar general de la misma, garantizando el derecho a la salud y por conexidad el derecho a la vida.

- Normas: son un segundo nivel de percepción donde se "definen las diferencias entre lo real percibido y lo real deseado" (Muller, 2010, p. 64), para la salud se encuentran definidas en leyes, resoluciones del Ministerio de Salud, decretos, documentos COMPES y sentencias de la Corte Constitucional, donde se definen los alcances del servicio de salud pública como un servicio prestacional, progresivo y que depende de la disponibilidad de recursos por parte del Estado.

- Algoritmos: son "relaciones causales que expresan una teoría de la acción” (Muller, 2010), con lo que se constituye el tercer nivel de percepción con la relación causaefecto, donde se abordan los determinantes en salud, elemento para garantizar el derecho a la salud y el bienestar general de la población.

- Imágenes: el último nivel se refiere a los "'atajos cognitivos' que le dan significación inmediata a lo que se hace" (Muller, 2010).

La política de salud puede ser pensada como una política social de bienestar social y ayuda social a los más desfavorecidos.

Ahora bien, a partir de estos elementos se identifica la lógica de regulación y el grado de influencia que tiene sobre la política secterritorial, sin embargo, aun así, se reconoce la mixtura entre las lógicas sectorial y territorial.

En este marco el análisis corresponde a la identificación de los grados de sectorialidad o territorialidad, a partir de la coherencia y concordancia entre los niveles de percepción, que indicarían la articulación o subordinación a alguna de las dos lógicas (figura 4). 
Figura 4. Articulación Secterritorial
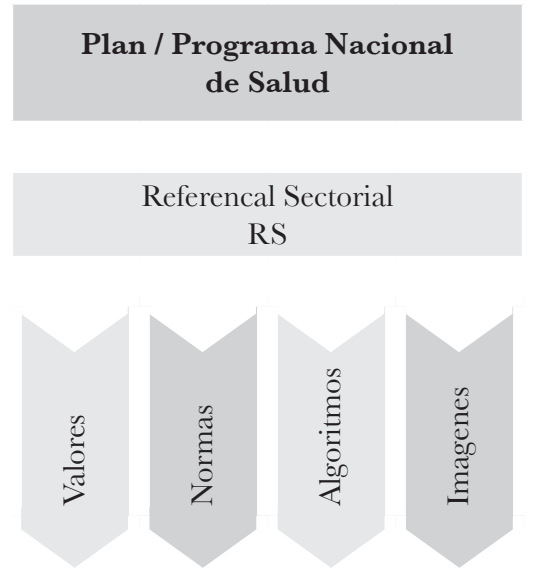

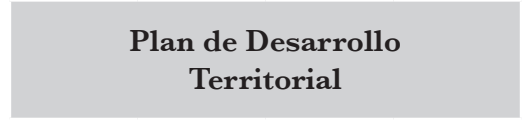

Referencal Territorial Global RTG

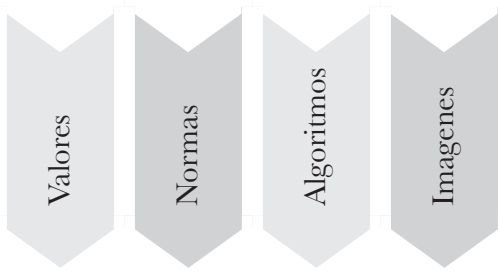

\section{Plan Secterritorial}

\section{Referencal Sectorial Territorial} RST

Plan de Salud

Territorial

\section{Referencal Territorial Sectorial \\ RTS}

Plan de

Ordenamiento

Territorial POT

Elaboración propia

El análisis cognitivo de las políticas públicas propuesto por Muller en relación a los RG y RS, y el desarrollado por Jolly en relación a los RGT, RST y RTS, permiten articular dos lógicas de regulación con los niveles de decisión y de percepción, definiendo así una metodología de análisis para el complejo intrincado de actores públicos que intervienen en decisiones en materia de la política social de salud.

\subsection{Análisis de la dimensión temporal de los instrumentos de salud pública}

\section{Sincrónico}

El análisis sincrónico busca identificar la concordancia o desfase que se da en los diferentes niveles y escalas de decisión en la política de salud pública, para lo cual se propone que a partir del referencial y los niveles de percepción de cada una de las políticas seleccionadas en el referente global, sectorial, territorial y sectorial territorial, se realice un análisis de relación y discrepancia (figura 5). 
Figura 5. Análisis Sincrónico de Políticas de Salud Pública

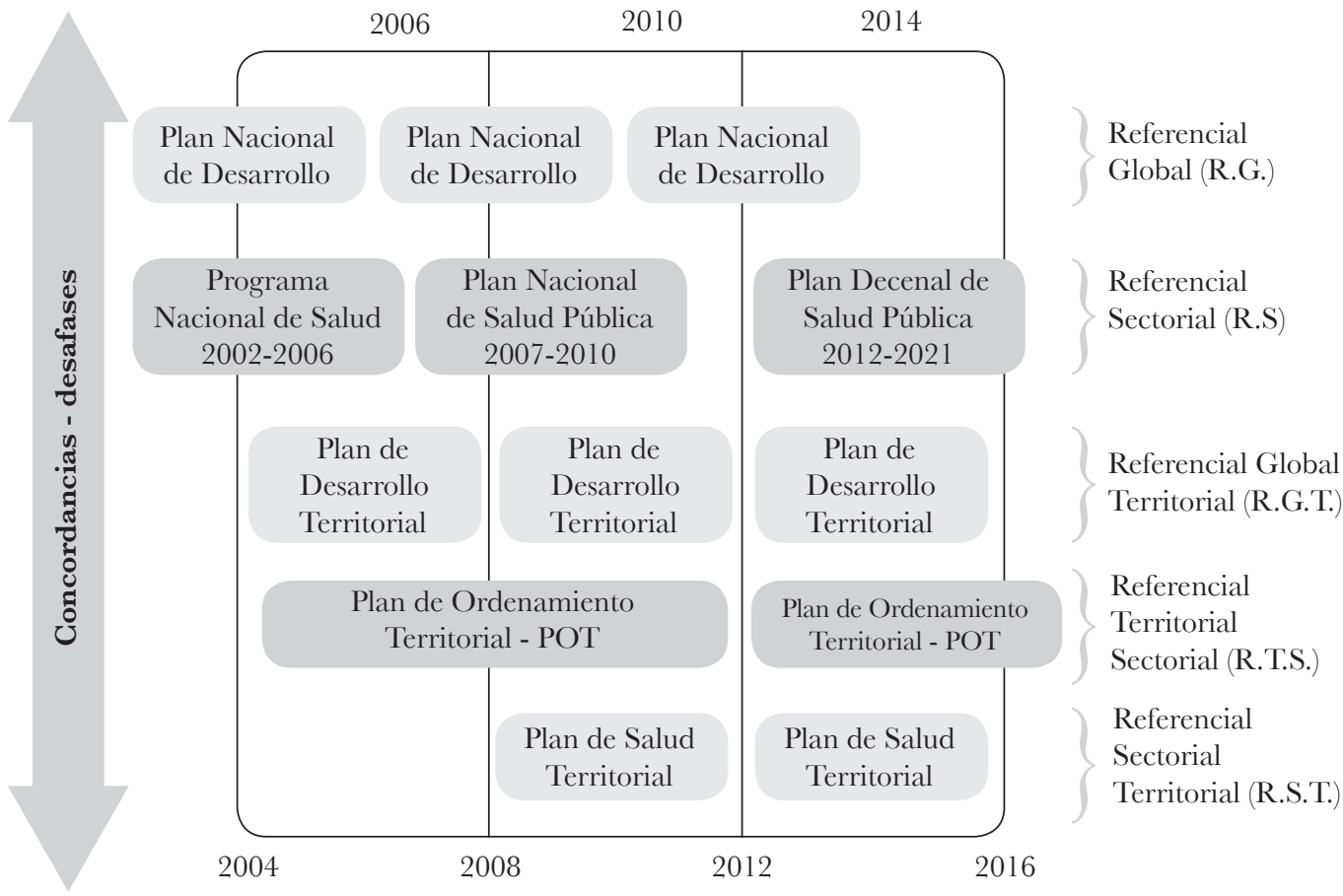

Elaboración propia

De este análisis se identifican, a nivel territorial, las acciones que se realizan por mayor capacidad económica y administrativa y que inciden en mayor cobertura y garantía a la salud, desde el componente de salud pública que implica acciones en prevención, saneamiento básico y prestación del servicio.

Es posible determinar el grado de territorialidad y de sectorialidad de una política pública en un momento dado y clasificar las políticas públicas según su grado de territorialidad y de sectorialidad, es decir, según la importancia relativa de sus lógicas de regulación (Jolly, 2012, p. 8).

Lo cual es relevante para el análisis territorial en salud y para lograr identificar en qué grado las actuaciones responden a una lógica determinada.

\section{Diacrónico}

El análisis diacrónico tiene como objetivo identificar la correspondencia o concordancia en las orientaciones de las políticas de salud pública en un territorio determinado, indicando la transformación de los valores, algoritmos, imágenes y acciones en salud. Para esto se toma el referente global territorial y el sectorial territorial (Figura 6). 
Hacia un esquema de análisis de la formulación de la política social de salud pública...

Figura 6. Análisis Diacrónico de Políticas de Salud Pública

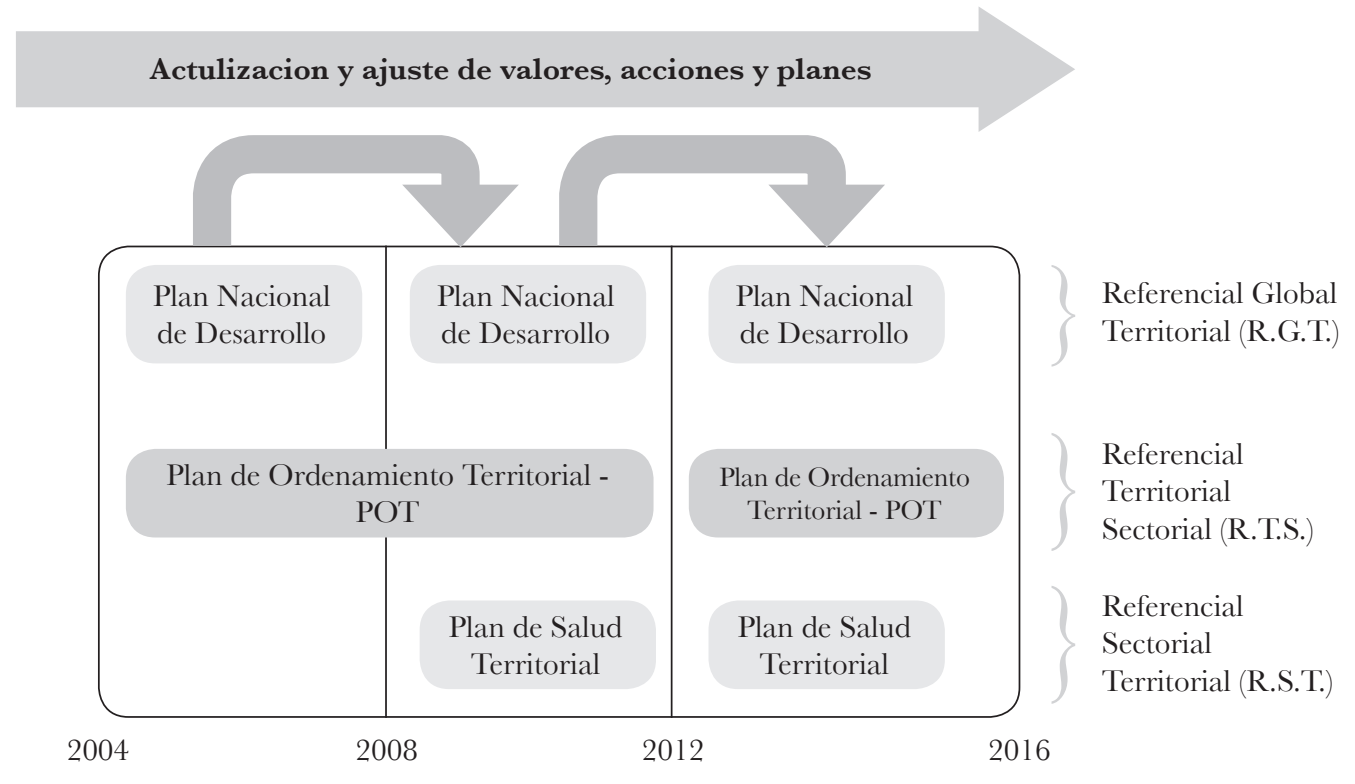

\section{Correspondencia o Concordancia}

Elaboración propia

Como se puede observar en las figuras 5 y 6 , el análisis de la coordinación sincrónica y diacrónica se fundamenta sobre los referenciales, para poder realizar la revisión de los niveles de percepción de cada uno de ellos y establecer si comparten valores como principios orientadores, algoritmos como relaciones causales de la situación no deseada o imágenes de los alcances y propósitos de los instrumentos de planificación.

\section{Análisis socio-territorial de la política social de salud pública}

Entendiendo el territorio según su función y su nivel de complejidad, Roa (2011) determina que se pueden asociar la recepción de la acción y el condicionante de la acción o instrumento de la acción, permitiendo así, la relación estrecha que se constituye con un espacio natural-físico; el nivel de complejidad se asocia a la acción humana, que se puede definir claramente en tres niveles: natural, equipado y organizado, los cuales por circunstancias históricas, económicas, sociales y culturales se transforman, adaptan o destruyen. 
Realizando una interpretación amplia y reconociendo condiciones históricas, el territorio supera el concepto de condicionante para convertirse en instrumento de las acciones, es así que su lectura se puede llevar a cabo a partir del principal instrumento de planificación que lo ordena y lo interpreta: El Plan de Ordenamiento Territorial-POT-.

Figura 7. Relación territorio

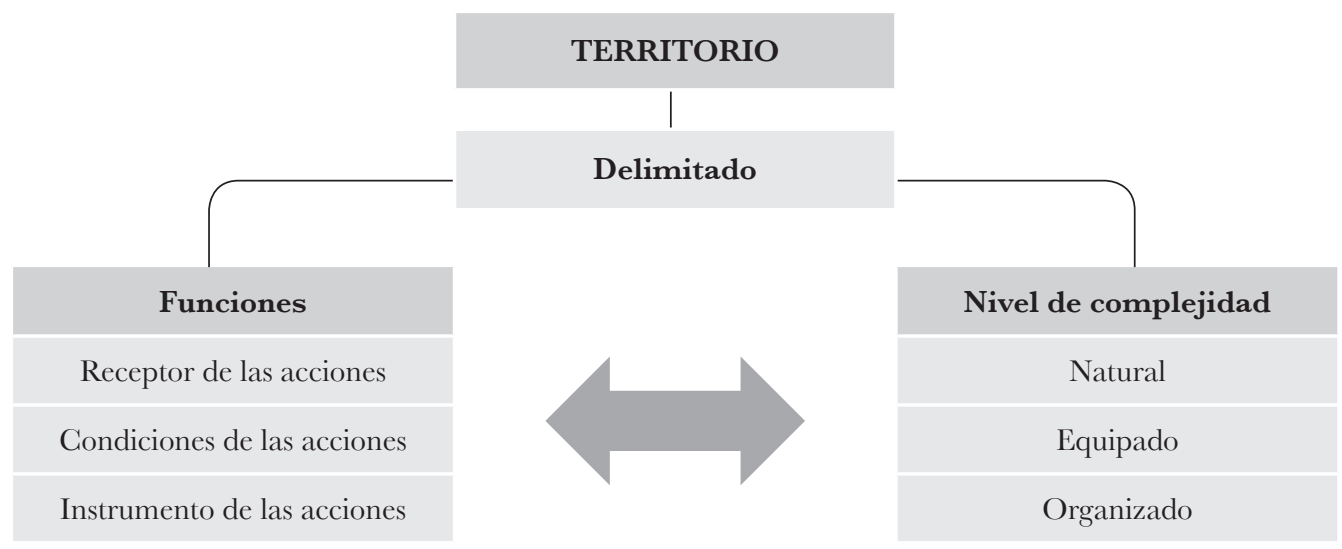

Fuente: Adaptación propia a partir de Roa (2011)

De acuerdo a lo expuesto en el capítulo uno, el territorio hace parte de un sistema socio-territorial en el cual se incluyen la territorialidad, como los valores atribuidos a un territorio. Los atributos sociales que se relacionan en primera medida con los valores del referencial territorial global (RGT) y los valores atribuidos a un sector en un territorio dado, que se define como los valores en el referencial sectorial territorial (RST), los cuales se articulan, adaptan y actualizan a medida que pasa el tiempo.

Figura 8. Relación territorialidad y atributos sociales

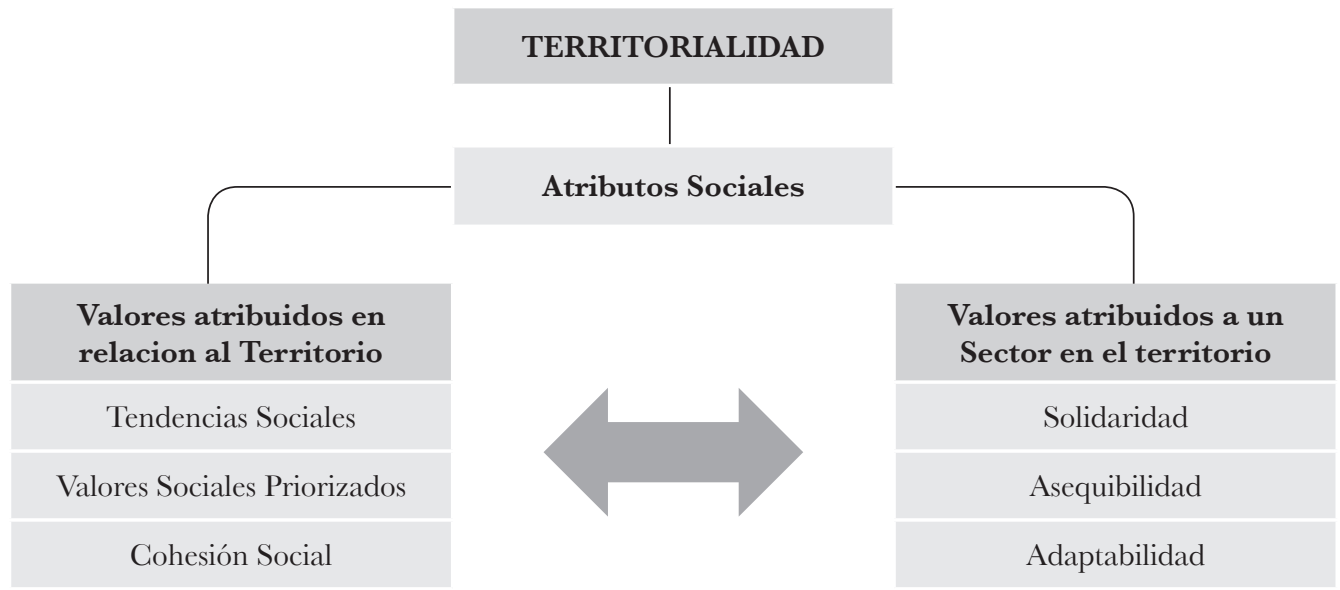

Fuente: Adaptación propia a partir de Roa (2011) 
En el sector salud los valores se pueden identificar de dos maneras: valores atribuidos al territorio y valores atribuidos a un sector. En este aspecto, estos guían las relaciones con el espacio físico y con las condiciones sociales, ya que son compartidos por la mayor parte de la población.

i bien los valores atribuidos a un sector no están relacionados con lo físico, sí define la forma y los propósitos que tiene un sector en un territorio, es por esta razón que se argumenta que al territorializar una política sectorial, esta asume particularidades que no podrán ser reproducidas o llevadas a otro territorio sin una adaptación previa.

Figura 9. Relación territorilización

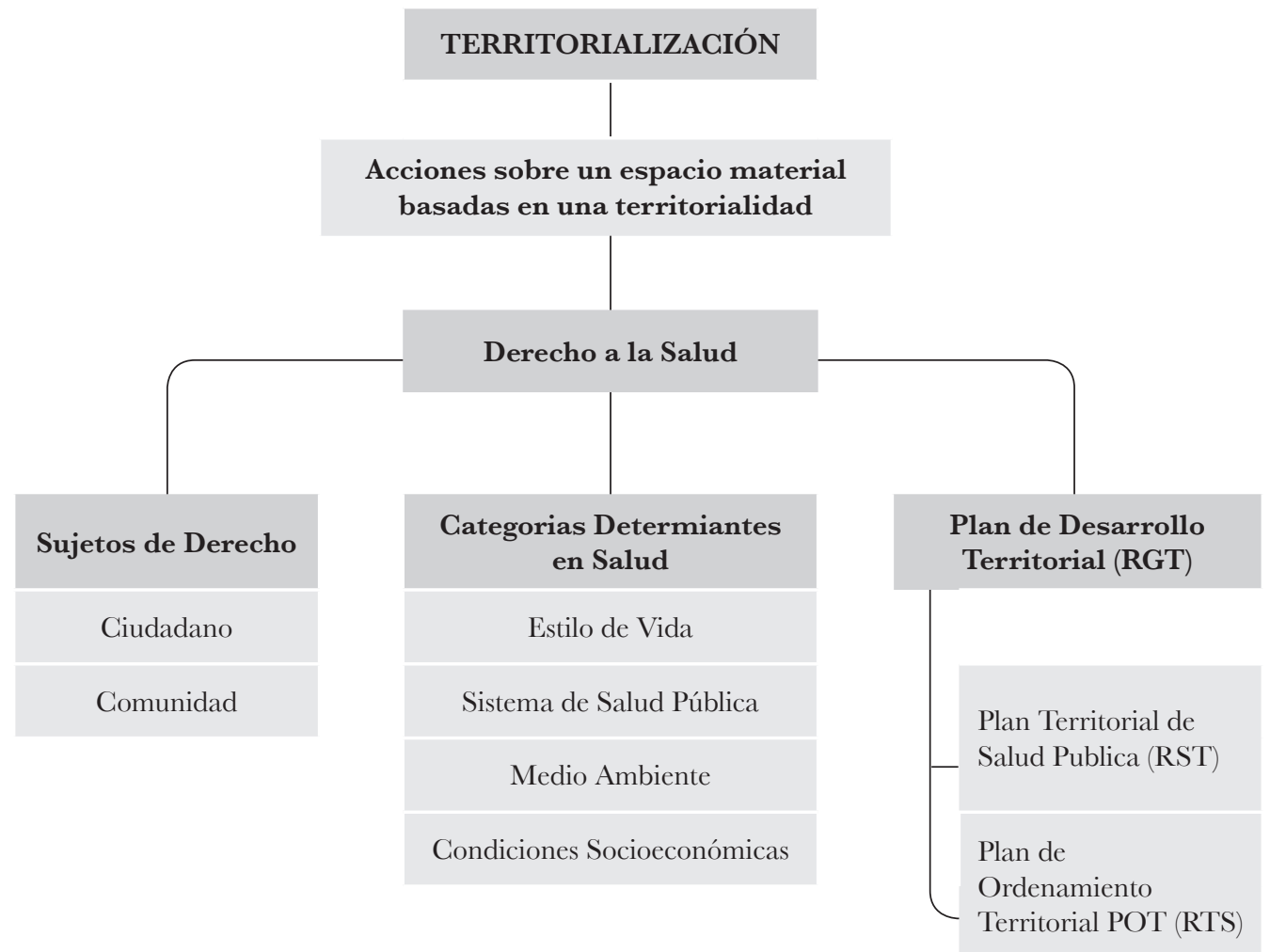

Elaboración propia a partir de Roa (2011)

La territorialización como la acción del Estado, se basa en la territorialidad y en los condicionantes del territorio, entendida a partir de la garantía al derecho de la salud, que se orienta a los ciudadanos y a la comunidad, desde el Plan de Desarrollo Territorial (RGT), el Plan Territorial de Salud Pública (RST) y el Plan de Ordenamiento Territorial (RTS) como se puede observar en la Figura 9. El impacto en el territorio y la territorialidad se entiende por medio de los determinantes en salud, haciendo una interpretación amplia de las acciones encaminadas a mejorar el bienestar. 
Descrito así cada uno de los componentes del análisis socio-territorial de la política social de salud pública, se articulan con el último componente: la territorialización, lo cual se puede observar en la figura 10.

Figura 10. Interdeterminación

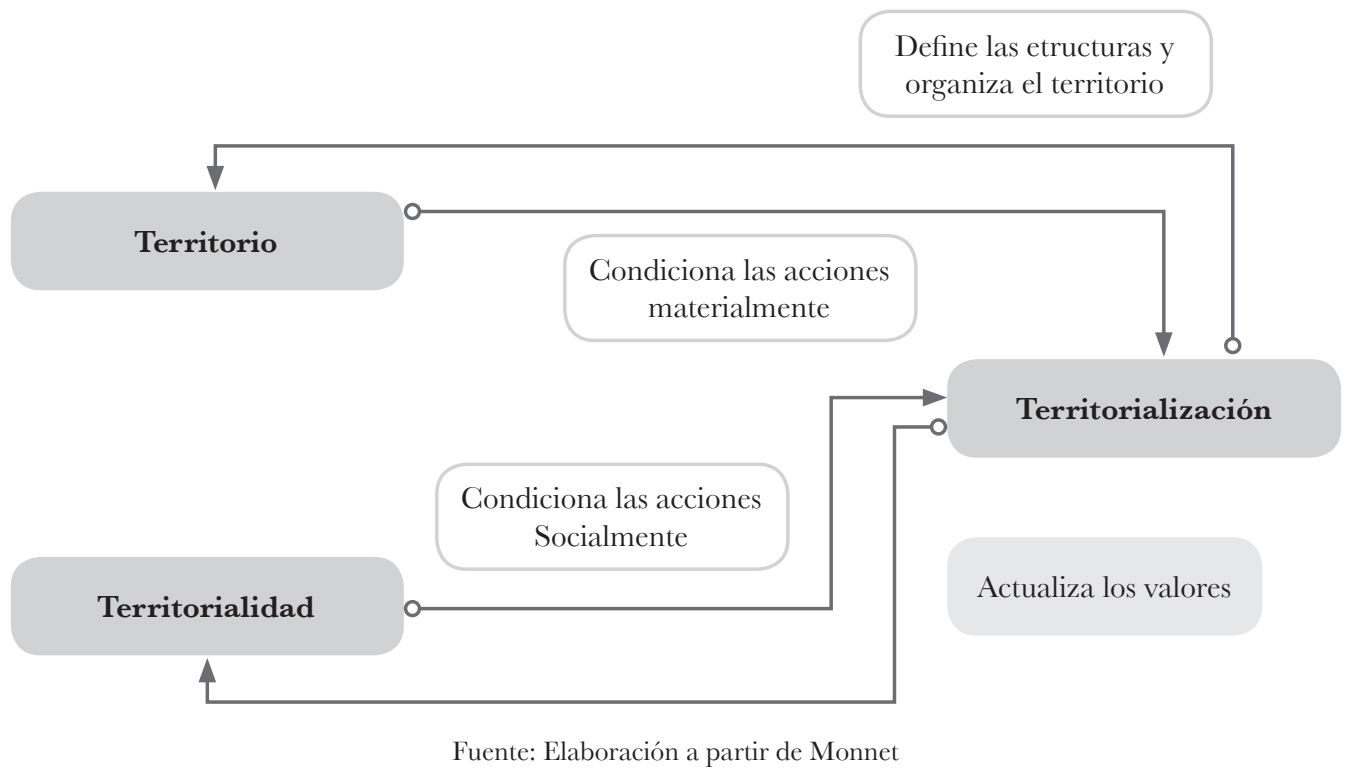

En esta variación de la propuesta de Monnet, se argumenta el elemento inductor de la territorialización, ya que modifica el territorio y actualiza los valores de la territorialidad en el mediano y largo plazo. La figura 10 describe claramente los condicionantes del territorio y la territorialidad sobre la territorialización, por consiguiente, para realizar las acciones se parte de unos condicionantes que se homologan con las categorías de determinantes intermedios de salud, expuestos en la figura 1 en el Nivel 4.

\section{Síntesis del esquema de análisis de la política social en salud desde un enfoque socio-territorial temporal}

El esquema de análisis es la síntesis de los conceptos expuestos en este capítulo, que se articulan por medio de dos elementos: el análisis cognitivo de las políticas públicas y los determinantes de salud, ambos elementos utilizan los instrumentos de planificación como objeto de análisis: El esquema se desarrolla en tres partes, la primera se refiere al análisis de coordinación sincrónica, que permite identificar la relación entre los instrumentos de planificación de diferentes niveles de decisión y regulación. La segunda parte se refiere a la lógica secterritorial que define los grados de sectorialidad o territorialidad en un instrumento de planificación. La tercera parte analiza la coordinación diacrónica, que 
Hacia un esquema de análisis de la formulación de la política social de salud pública...

permite identificar la relación de los referenciales con el territorio y su transformación entre dos o más instrumentos de planificación en el tiempo.

Figura 11. Esquema general de análisis

\section{Análisis cognitivo de las políticas públicas a través} de los instrumentos de planificación

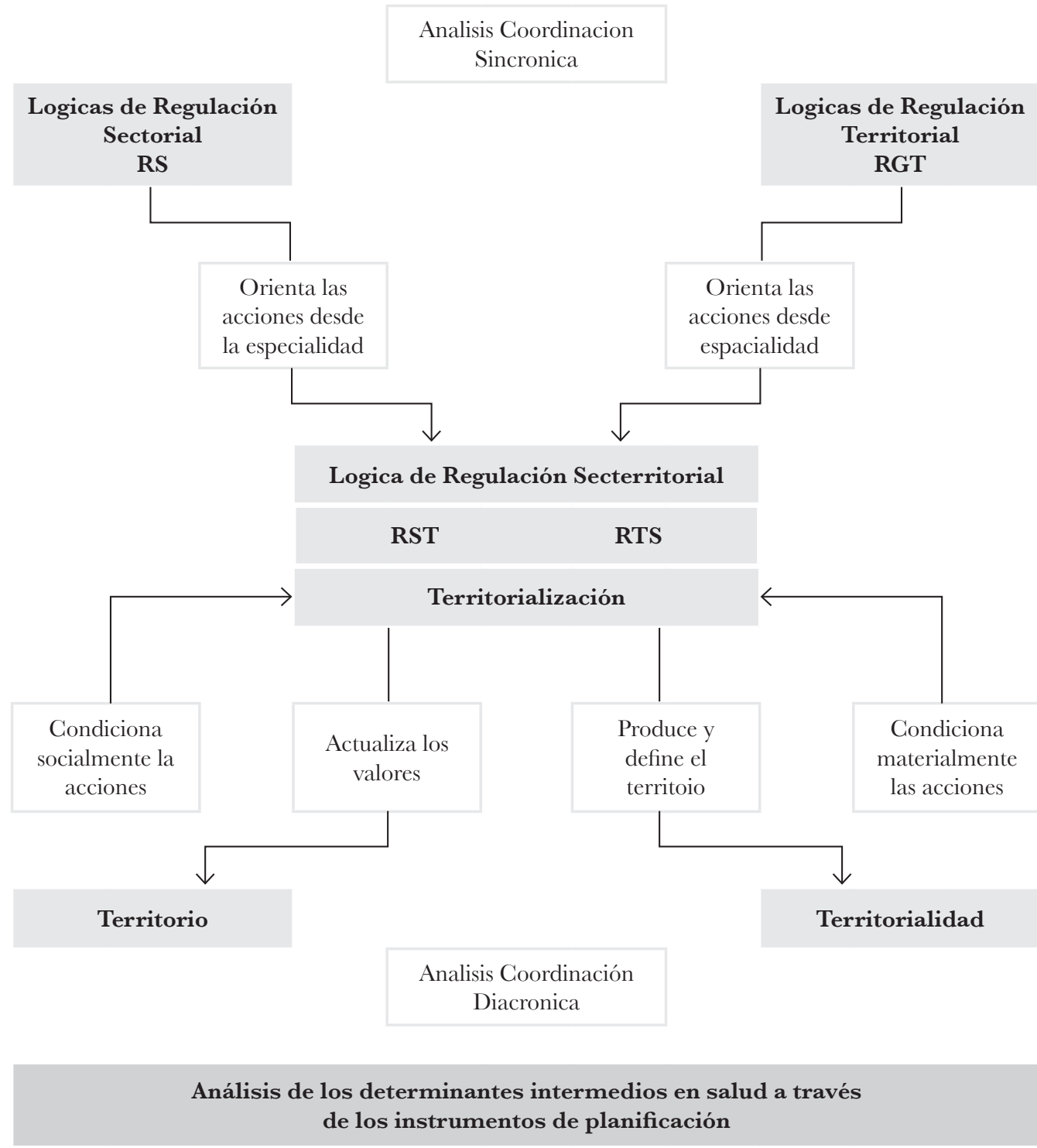

Elaboración propia 
La primera parte del esquema de análisis se enfoca en la coordinación sincrónica en un punto específico del tiempo, para lo cual se identifican valores, algoritmos e imágenes en los referenciales en relación a las categorías definidas en los determinantes en salud, esto permite identificar las concordancias y desfases entre los instrumentos de planificación en diferentes niveles de decisión y bajo dos lógicas disimiles, una orientada desde la especialidad (RS) y la otra desde el territorio (RGT). El principal resultado se basa en la identificación del grado de articulación y el desfase que se encuentra entre los referenciales y los niveles de percepción en la política social de salud pública.

La segunda parte del análisis se centra en las relación entre las dos lógicas y las acciones sobre el territorio y la territorialidad, en este aspecto se parte de la secterritorialidad representada por los Referenciales Sectorial Territorial (RST) y el Referenciales Territorial Sectorial (RTS), en los cuales se puede determinar, según Jolly, el grado de sectorialidad o territorialidad de los instrumentos de planificación descritos. Esto constituye el elemento central y articulador entre las lógicas de regulación y la inter-determinación en el territorio propuesta por Monnet.

La tercera parte del análisis utiliza la coordinación diacrónica, para definir los cambios en el referencial global territorial (RGT), el RST y el RTS, los cuales solo se perciben y se pueden identificar al transcurrir las acciones en el tiempo. En este caso se identificará la continuidad o las rupturas en los niveles de percepción, a partir de los cambios marginales y paulatinos que pueden llegar a ser imperceptibles pero determinantes para la transformación social y la ampliación de las garantías al derecho a la salud, en un territorio dado.

El propósito del esquema no es generar un juicio de valor sobre el sistema de salud pública nacional o territorial, sino ser un elemento que facilite el análisis de la salud pública en los territorios y permita mayor comprensión de los cambios y de las dinámicas a los cuales se ve sometido.

\section{Conclusiones}

La diversidad de actores que intervienen en el desarrollo de las políticas de salud, tanto públicas como privadas, impone retos de articulación y de regulación, ya que estos actúan con lógicas disimiles, intereses y relaciones de poder asimétricas. En este aspecto los procesos de planeación son claves para lograr superar las barreras de acceso y de cubertura, y así, cumplir con la progresividad en la garantía del derecho a la salud. En Colombia el proceso de descentralización ha delegado funciones a los entes territoriales para incluir los procesos de participación de los ciudadanos en la toma de decisiones, articulando la realidad especifica de un territorio con los procesos de salud. 
El generar un proceso de reflexión de la salud pública frente a las lógicas de regulación a las cuales se ve influida, ha sido enriquecedor para entender cómo los procesos de descentralización llevados en Colombia han permitido diversificar las miradas frente a la salud y el rol de los actores en el sistema, esto sin desconocer que el SGSS restringe la ejecutividad de los resultados. Aun así, los entes territoriales han realizado avances significados, como el desarrollo del enfoque de determinantes, la reducción de inequidades y la Atención Primaria en Salud (APS), avances que han sido una alternativa para algunas ciudades, ya que su coherencia y efectividad, han propiciado cambios en la política de salud a nivel sectorial y nacional.

El esquema de análisis permitirá evidenciar las relaciones entre los instrumentos de planificación y su transformación en el tiempo. Es clave entender que el esquema es una primera reflexión que se realiza para entender las interrelaciones entre territorio territorialización y territorialidad, tomando como base las lógicas de regulación sectoriales y territoriales que se han constituido dentro del sistema de gobernabilidad híbrido entre centralismo y descentralización con el que cuenta Colombia. Desde este punto de vista, uno de los mayores atributos y aportes del esquema es poder decodificar en dos sistemas de coordinación la política social de salud pública, uno que tiene en cuenta las escalas de decisión y otro que permite identificar la coherencia de las políticas en el tiempo, esto basado en los proyectos de territorio y su relación con los valores propios de una comunidad.

El esquema es una primera mirada a los procesos de planificación territorial en salud pública en un contexto general, esto definido y esquematizado por los instrumentos de planificación en dos lógicas predominantes sectorial y territorial, identificando los componentes RST y RTS, que permitirá esquematizar en otras investigaciones las relaciones de poder y conflictos alrededor de los componentes sociales, políticos y económicos en los procesos de identificación, planificación, implementación y evaluación de las acciones en el modelo de salud pública.

El análisis de los instrumentos de planificación permitió identificar el rol que juega la salud pública en un círculo de decisión política, que bien puede ser nacional o territorial. La aplicación aún somera del esquema a las acciones y resultados desarrollados en las ciudades como Medellín y Bogotá, ha permitido cuestionar las directrices sectoriales que se sustentan en modelos tradicionales de salud. Deja vislumbrar además que la gran dificultad frente a la sostenibilidad en el financiamiento de la salud pública se puede superar, toda vez que se cambie el enfoque de atención a la enfermedad que es difundido por el SGSS.

La identificación de procesos territoriales de salud, que amplían y garantizan el derecho a la salud, en la medida en que las competencias y recursos permiten definir líneas de acción más amplias que las definidas en los instrumentos sectoriales o nacionales. Esto a la vez visibiliza que los procesos de salud entre las regiones no son iguales frente al 
acceso a la disponibilidad y a la garantía para la salud. Esto lleva a pensar que sería interesante indagar las diferencias en relación con los recursos de libre destinación con los que cuentan las regiones.

El análisis cognitivo esbozado aquí permite avanzar la hipótesis que los mediadores en salud pública, entre las lógicas de regulación sectorial y territorial, deben ser más efectivos y definir unas competencias que permitan el desarrollo de la salud en Colombia de una forma más equilibrada y propiciar así avance científico. La reflexión en este aspecto puede propiciar la discusión amplia frente a las responsabilidades territoriales en los sistemas de salud de alta complejidad, investigación y desarrollo, al igual que los compromisos sectoriales en relación a la promoción de la salud y administración de los recursos en el SGSS.

Las tendencias europeas y anglosajonas han dado relevancia a la salud pública abordada desde un enfoque territorial, ya que esta supera las discusiones relacionadas a la administración de la oferta en salud. Es así como la investigadora canadiense Clavier (2012) relaciona la salud con el fortalecimiento de la gobernanza en las ciudades y al abordaje de la salud como un problema de soluciones integrales. Una visión intersectorial de la salud permite a las regiones y a las ciudades poner la salud como un nodo articulador del desarrollo social, donde las secretarias de salud o direcciones de salud, son participes en propuestas de movilidad, educación, saneamiento básico, vivienda y finanzas, debido a las ventajas que tiene la articulación de necesidades poblacionales a hábitos de vida saludables, como hábitats saludables, sistemas de movilidad -caminatas o recorridos en bicicleta-, promoviendo conductas que respondan al auto-cuidado.

En términos territoriales las acciones en salud pública, deben identificar las relaciones que se dan entre los actores y los micro territorios que habitan, toda vez que los territorios no solo constituyen unidades administrativas, sino son el medio del sostenimiento de la vida humana y en ellos se dan significados a las relaciones sociales y económicas de formas innovadoras y creativas que son propias de ciudades, pueblos y territorios dinámicos.

La salud pública no solo es un asunto de medios, sino por el contrario es un reto social que involucra a toda la sociedad en su transformación: enfoques como la APS son bastante progresivos y amplios, permiten definir un propósito social para la salud, que contenga el cuidado del medio ambiente, con el fin de concientizar las instituciones frente a los procesos en salud, desarrollando mayor equilibrio entre las competencia nacional y territorial en relación a la salud, sin que se esté promoviendo mayor descentralización, sino que al contrario se definan de forma equilibrada las cargas en la administración de la oferta en salud, de la promoción y de la prevención en relación a los recursos destinados para este fin, y finalmente, definir competencias de prestación de servicios en las entidades de carácter privado. 
Finalmente los instrumentos en planificación en salud pública hasta ahora han sido mecanismos normativos para ejecución de recursos y fijación de metas, estos se deben considerar más como herramientas para la transformación del sector salud y de los territorios, con esta investigación que aborda la salud pública desde un enfoque innovador por los supuestos de partida, es necesario realizar una revisión amplia de los mediadores (actores en salud) entre las lógicas y los procesos de negociación en el sistema de salud, esto debido a que claramente se devela en el trabajo que los planes no solo se articulan a una lógica sectorial o territorial, sino a un referencial de mercado y a unos actores de presión política y económica. 


\section{Referencias}

Agudelo Suárez, L. [et al.] (2000). Fundamentos de salud pública. Medellín, s.e.

Antioquia, Alcaldía de Medellín, [en línea]. Recuperado de: http://www.medellin.gov. co/irj/portal/medellinhttp://www.medellin.gov.co/irj/portal/ciudadanos?Navigat ionTarget=navurl:/ /95df34b57f5f0fd3189aa242d8586a05

Antioquia, Gobernación de Antioquia, [en línea]. Recuperado de: http://antioquia. gov.co/

Bejarano Mayorga, C. (2012). Hacia un esquema para el análisis del referencial de las políticas públicas urbanas, desde la perspectiva de los instrumentos de planificación y de gobierno, como instrumentos de acción pública [tesis de maestría]. Bogotá, Pontifica Universidad Javeriana, Maestría en Planeación Urbana y Regional.

Bogotá, Secretaria Distrital de Hacienda (2012). Presupuesto. Bogotá, Distrito Capital, Imprenta Distrital.

Chávez B, Sierra O, Lopera M, Montoya P. (2004). El Plan de Atención Básica en los municipios descentralizados de Colombia, 2001-2003. Rev. Facultad Nacional de Salud Pública, pp. 77-99.

Colombia, Corte Constitucional (1992). Sentencia T-484, MP. Simón Rodríguez Rodríguez y Jaime Sanín Greffenstein. Bogotá.

- (1998). Sentencia T489, MP. Bladimiro Naranjo Mesa, Bogotá.

Colombia, Ministerio de la Protección Social (2007-2010). Plan Nacional de Salud Pública, Imprenta Nacional.

- Sistema de la Protección Social. Componente Territorial, Imprenta Nacional.

Colombia. Congreso de la República. Constitución Política de Colombia de 1991.

Colombia, Departamento Nacional de Planeación (DNP), Documento Conpes social 22. Focalización del gasto social en las entidades territoriales, Imprenta Nacional.

Colombia, Departamento Nacional de Planeación (DNP), Documento Conpes social 133. Distribución de los recursos pendientes de las once doceavas del SGP. 2010. Componente: Educación en salud, Imprenta Nacional.

Colombia, Ministerio de la Protección Social (2010). Análisis de la situación en salud en Colombia, Imprenta Nacional. 
Colombia, Ministerio de la Protección Social (2007). Encuesta nacional de salud, Imprenta Nacional.

Colombia, Ministerio de la Protección Social (2008). Resultados por departamentos: Bogotá, Imprenta Nacional.

Colombia, Ministerio de la Protección Social (2008). Resultados por departamentos: Antioquia, Imprenta Nacional.

Colombia, Ministerio de la Protección Social (2008). Guía para la construcción de los panes de salud territoriales, Imprenta Nacional.

Colombia, Ministerio de la Protección Social (2003). Programa Nacional de Salud: 20022006, Imprenta Nacional.

Comisión sobre determinantes sociales de la salud (2008), Informe sobre determinantes sociales de la salud. Resumen analítico, OMS, Ginebra.

Correa Montoya, L. (2011). Planeación participativa para la garantía del derecho a la ciudad: análisis del proceso de formulación, discusión y elaboración del plan centro de Bogotá (Colombia), [tesis de maestría]. Bogotá, Pontifica Universidad Javeriana, Maestría en Planeación Urbana y Regional.

Departamento Nacional de Planeación (DNP) (1993). El gasto público en saludy distribución de subsidios en Colombia. Bogotá, DNP.

Departamento Nacional de Planeación (DNP) (2011). Planeación para el desarrollo integral en las entidades territoriales: Plan de desarrollo 2012-2015. Bogotá, DNP.

Dirección general de salud pública. Consejería de salud del principado de Asturias (2009). Análisis de la situación de la salud en Asturias. Asturias.

GTZ (2007). Orientaciones metodológicas para la planificación territorial. El salvador, s. e.

Guerrero, R. (2006) El concepto de la protección social, en Cuadernos de Protección social. Bogotá, Núm. 3. pp. 2-20.

Molina G, Montoya N, Rodríguez G, Spurgeon P. (2006). Descentralización del sector Salud en Colombia: un análisis de 91 municipios. Medellín, Rev. Facultad Nacional de Salud Pública, pp. 48-60.

Monnet, J. (2010). Le territoire réticulaire en Revista Anthopos, huellas del conocimiento. Número 227. Abril-junio de 2010. Barcelona, España. pp. 91-104. 
Muller, P. (2010). Las políticas públicas. Bogotá, Universidad Externado de Colombia, traducción Jean-Francois Jolly y Carlos Salazar Vargas.

- (2010). Las Políticas Públicas. Jolly, Jean Francois y Salazar Vargas, Carlos (traductores). Universidad Externado de Colombia. Bogotá. 2010. Tercera edición.

- (2009). Referencial en BOUSSAGUET, Laurie, Jacquot, Sophie y Ravinet, Pauline (dirs). Diccionario de Políticas Públicas. Universidad Externado de Colombia. Bogotá. 2009.

Jaramillo, M. (s. a). La planeación territorial en salud como un componente del Plan de desarrollo municipal, en Revista Polis, s.d.

Jolly, J. (2010). Regir el territorio y gobernar los territorios. Bogotá, Pontificia Universidad javeriana.

- (2003). Pequeños municipios y descentralización, enfoque político vs. enfoque económico, en Meyer, H. et. al. Problemática de los pequeños municipios en Colombia isupresión o reforma? Universidad Externado de Colombia y Konrad-Adenauer-Stiftung. Bogotá. 2003.

- (2010). Por un plan de movilidad urbana de Bogotá con un enfoque de oferta. Texto sin publicar.

- (2007). Territorialidady sectorialidad de las políticas públicas. Aspectos analíticos y utilizaciones normativas de un esquema de análisis de las políticas públicas en el territorio, en Guervo et al. Ensayos sobre políticas públicas. Universidad Externado de Colombia. 2007.

- (2010). “Existe un enfoque francés de política pública?”, en Arrubla, D. y Ballesteros, M. (comps.), Enfoques para el análisis de políticas públicas, 2010, Bogotá, Universidad Nacional de Colombia.

- (2012). Gobernanza de los y en los territorios y desarrollo económico local. Bogotá, el autor.

- (2004). Regir le territoire et gouverner les territoires la politique publique de décentralisation: en colombie entre 1982 et 2002, [tesis doctoral], Soutenue, Universite de paris iii la sorbonnenouvelle: institut des hautes etudesd'amerique latine-iheal. Doctorat Études des sociétés latino-américaines.

Molina, G. (2007). La descentralización del sector salud en Colombia, en Revista Gestión y Política pública, núm. 1, vol. 16, pp. 171-202. 
Molina, G. (2006) Descentralización del sector salud en Colombia: análisis de 91 municipios, en Revista de la Facultad Nacional de Salud Pública, núm. 1, Vol. 24, pp. 48-60.

Navarro, V. (s. a). Concepto actual de la salud pública, [en línea]. Recuperado de: http://uiip. facmed.unam.mx/deptos/salud/censenanza/spi/fundamentos/navarro.pdf

Ortiz, I. (2007). Política social. New York, Naciones Unidas.

Organización Mundial de la Salud-OMS-. 1990. Principios de higiene de la vivienda.

Pasquier, R.; Guigner, S.; Cole, A. (2010). Dictionnarie des politiques territoriales, s. l., Centre de recherche sur l'actionpolitique e Europe.

Puello-Socarrás, J. (2007). La dimensión cognitiva en las politicas públicas, en Revista Ciencia Política, núm. 3, pp. 30-57.

Roa Bernal, P. (2011). La territorialidad de los Derechos Humanos. La planeación del desarrollo territorial, un instrumento para su territorialización, [informe de investigación]. Bogotá, Pontifica Universidad Javeriana, Facultad de Arquitectura y Diseño.

Rodríguez, P. (2009). Medellín. La ciudad y su gente, en Revista Credencial Historia, núm. 230. 2009.

Roth Deubel, A. (2010). "Las politicas públicas y sus principales enfoques analíticos", en Arrubla, D. y Ballesteros, M. (comps.). Enfoques para el análisis de políticas públicas, 2010, Bogotá, Universidad Nacional de Colombia.

- (2007). Enfoques y teorías para el análisis de las políticas públicas, cambio de la acción públicay transformaciones del Estado, en Cuervo et al. Ensayos sobre políticas públicas. Universidad Externado de Colombia. 2007.

- (2006). Discurso sin compromiso. La política pública de derechos humanos en Colombia. Ediciones Aurora. Bogotá. 2006.

Salazar Vargas, C. (2011). Políticas Públicas, México, Mariel.

Sen, A. La Idea de la fusticia. Taurus. Bogotá, 2010.

Sentencia T-60 (2012). [en línea]. Recuperado de: http://www.corteconstitucional.gov. co/T-760-08/Autos\%20genericos/AutosGenericos.php

Suarez, E. (2003). Políticas de la salud colombiana en los modelos de desarrollo, en Revista Investigación en enfermería, imagen y desarrollo, vol. 5, p p. 29-39. 


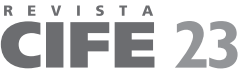

ISSN: 0124-3551 / Año 15, No 23 / julio-diciembre / pp. 123-152

Vélez, A. (2009). El derecho a la salud: políticas públicas y percepción de autores, en Revista Hacia la promoción de la salud, vol. 14, núm 1, pp. 68-92.

Whitehead, M.; Dahlgren, G.; Gilson, L. (2001). Developingthepolicy response toinequities in Health: a global perspective. In Challeng in ginequities in healthcare: from ethics to action. New York, Oxford University Press, pp. 309-322. 